\title{
Two-dimensional Co-Seismic Surface Displacements Field of the Chi-Chi Earthquake Inferred from SAR Image Matching
}

Jun Hu ${ }^{1}$, Zhi-Wei Li ${ }^{1,}{ }^{*}$, Xiao-Li Ding ${ }^{2}$ and Jian-Jun Zhu ${ }^{1}$

${ }^{1}$ School of Info-Physics and Geomatics Engineering, Central South University, Changsha 410083, Hunan, P.R. China; E-mails: 36185443@163.com; zjj@mail.csu.edu.cn

2 Department of Land Surveying and Geo-Informatics, The Hong Kong Polytechnic University, Hung Hom, Kowloon, Hong Kong, P.R. China; E-mail: 1sxlding@polyu.edu.hk

* Author to whom correspondence should be addressed; E-mail: rszwli@gmail.com

Received: 10 June 2008; in revised form: 14 August 2008 / Accepted: 20 October 2008 / Published: 21 October 2008

\begin{abstract}
The $M_{w}=7.6$ Chi-Chi earthquake in Taiwan occurred in 1999 over the Chelungpu fault and caused a great surface rupture and severe damage. Differential Synthetic Aperture Radar Interferometry (DInSAR) has been applied previously to study the co-seismic ground displacements. There have however been significant limitations in the studies. First, only one-dimensional displacements along the Line-of-Sight (LOS) direction have been measured. The large horizontal displacements along the Chelungpu fault are largely missing from the measurements as the fault is nearly perpendicular to the LOS direction. Second, due to severe signal decorrelation on the hangling wall of the fault, the displacements in that area are un-measurable by differential InSAR method. We estimate the co-seismic displacements in both the azimuth and range directions with the method of SAR amplitude image matching. GPS observations at the 10 GPS stations are used to correct for the orbital ramp in the amplitude matching and to create the two-dimensional (2D) co-seismic surface displacements field using the descending ERS-2 SAR image pair. The results show that the co-seismic displacements range from about $-2.0 \mathrm{~m}$ to $0.7 \mathrm{~m}$ in the azimuth direction (with the positive direction pointing to the flight direction), with the footwall side of the fault moving mainly southwards and the hanging wall side northwards. The displacements in the LOS direction range from about $-0.5 \mathrm{~m}$ to $1.0 \mathrm{~m}$, with the largest displacement occuring in the northeastern part of the hanging wall (the positive direction points to the satellite from ground). Comparing the results from amplitude matching with those from DInSAR, we can see that while only a very small fraction of the LOS displacement has been recovered by the
\end{abstract}


DInSAR mehtod, the azimuth displacements cannot be well detected with the DInSAR measurements as they are almost perpendicular to the LOS. Therefore, the amplitude matching method is obviously more advantageous than the DInSAR in studying the Chi-Chi earthquake. Another advantage of the method is that the displacement in the hanging wall of the fault that is un-measurable with DInSAR due to severe signal decorrelation can almost completely retrieved in this research. This makes the whole co-seismic displacements field clearly visible and the location of the rupture identifiable. Using displacements measured at 15 independent GPS stations for validation, we found that the RMS values of the differences between the two types of results were $6.9 \mathrm{~cm}$ and $5.7 \mathrm{~cm}$ respectively in the azimuth and the range directions.

Keywords: Chi-Chi earthquake, Differential Synthetic Aperture Radar (DInSAR), amplitude image match, GPS, Two dimensional (2D) displacements

\section{Introduction}

On 21 September 1999, a $M_{w=7.6}$ earthquake occurred near Chi-Chi Town in Taiwan. The devastating earthquake was triggered by the reactivation of the north-south-trending Chelungpu fault and caused an approximately $80 \mathrm{~km}$ long surface rupture along the Chelungpu fault [1]. More than 2,000 people died in the earthquake and 53,551 buildings were destroyed [2].

Differential Interferometic Synthetic Aperture Radar (DInSAR) has been used to measure the coseismic displacements of the earthquake. Pathier et al. [3] found about 10 interferometric fringes in a differential interferogram spanning the earthquake. The fringes are equivalent to about $0.28 \mathrm{~m}$ surface displacements in the LOS direction at the footwall of the Chelungpu fault. Liu et al. $[4,5]$ reported that the largest LOS displacements in the footwall of the Chelungpu fault calculated from an averaged interferogrm was about $0.33 \mathrm{~m}$. In these DInSAR studies however, only one-dimensional displacement along the radar Line-of-Sight (LOS) direction were determined. As the Chelungpu fault strike is nearly parallel to the azimuth direction (with an angle of about $12^{\circ}$ ), the LOS measurements are insensitive to the displacements along the fault strike. In addition, the severe loss of coherence (coherence is defined as the amplitude of the complex correlation coefficient between two patches of co-registratered SAR images, see e.g. [6]) on one side of the fault make it very difficult to determine the displacements with the DInSAR method in the area. Global Positioning System (GPS) has also been used to study the displacements caused by the earthquake although it offers much lower spatial resolution compared with that of the InSAR method. For example, Yu et al. [7] reported that 2.4-10.1 m horizontal displacements and 1.2-4.4 m vertical displacements were observed with GPS across the Chelungpu fault. In general, displacements of such magnitudes are difficult to be measured with $\mathrm{C}$ - or X-band DInSAR method as the displacements may cause mis-registrations of images and result in fringe rates exceeding the saturation threshold of half a fringe per pixel, which will lead to severe signal decorrelation $[8,11]$. Such disadvantages of the DInSAR method have been the motivation to study the ground displacements of the earthquake with the SAR amplitude image matching [8-10] and SPOT image matching methods [22]. 
We will first present results of co-seismic ground deformation measurements from DInSAR method, followed by those from the method of SAR amplitude images matching. By combining the Azimuth Offset (AZO) and the Range Offset (RO) of the SAR amplitude images, a two-dimensional (2D) surface displacement fields associated with the earthquake will be generated. The results will be compared with GPS observations at some GPS stations in the study area.

Figure 1. Location of the Chi-Chi earthquake in the WGS 84 system (all figures presented in this paper are in the same reference system except otherwise stated). The red star represents the position of the epicenter. The yellow line represents the Chelungpu fault [7]. The white rectangle indicates the area covered by the ERS-2 descending SAR images used in this study.

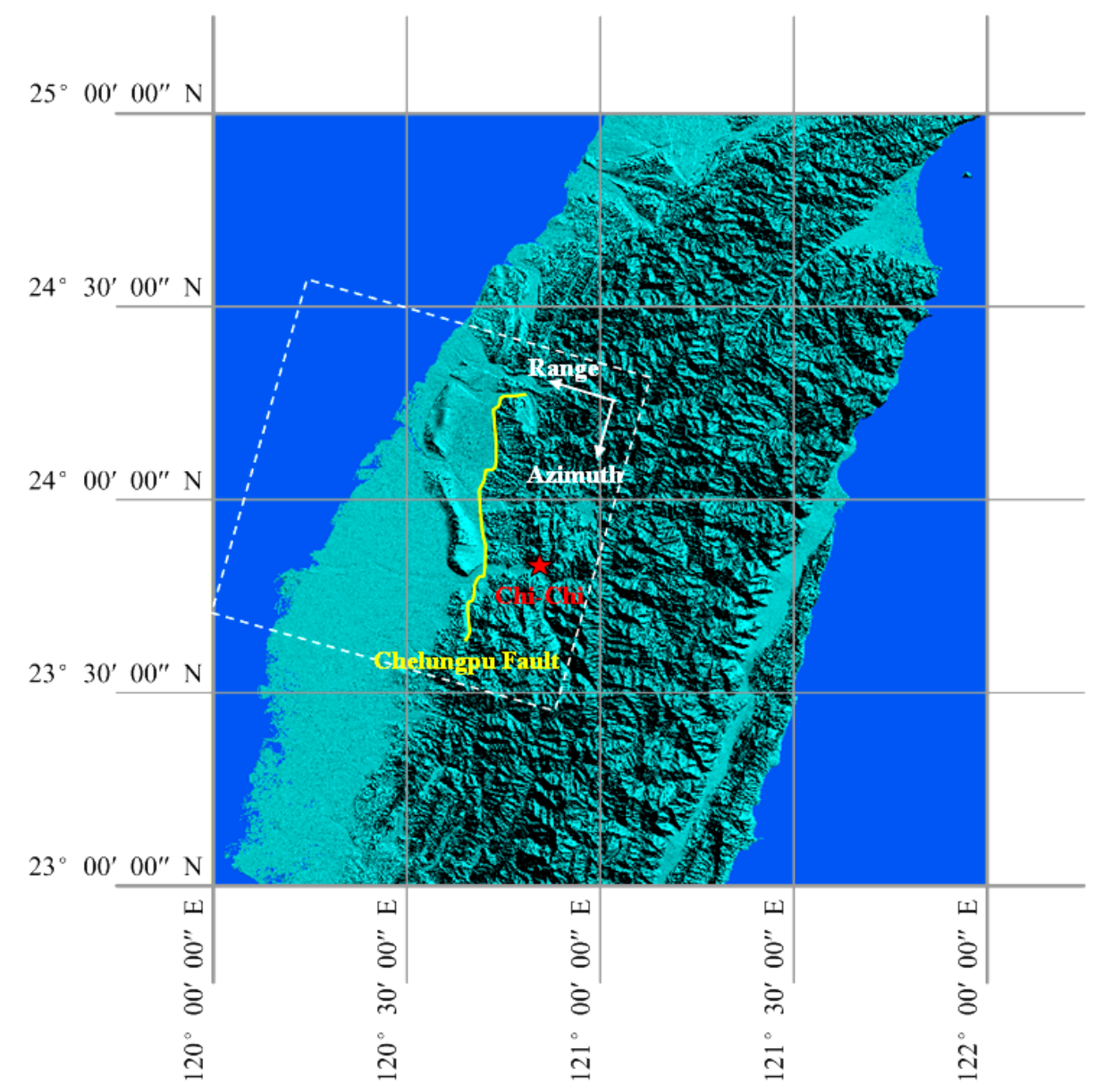

\section{Data Analysis}

\subsection{Analysis of Co-Seismic Interferogram}

Two $\mathrm{C}$ band $(\lambda=5.6 \mathrm{~cm})$ ERS-2 satellite SAR images (Table 1) are used to study the co-seismic ground displacements of the Chi-Chi earthquake. The angle of incidence of the radar sensor is about 23 degrees, and the satellite revisit time is 35 days. The images are both from descending orbit, one acquired before the earthquake and the other after the earthquake. Although some ascending SAR images are also available, their time spans are too long to produce meaningful interferograms or offset 
images. They are therefore not used for this study. The location of the descending SAR images is shown in Figure 1.

Table 1. ERS-2 SAR data used.

\begin{tabular}{|l|l|l|l|l|}
\hline No. & Date & Orbit & Frame & Track \\
\hline 1 & 15 July 1999 & 22130 & 3123 & 232 \\
2 & 28 October 1999 & 23633 & 3123 & 232 \\
\hline
\end{tabular}

The SAR images are first processed with the two-pass DInSAR method and the GAMMA software [12]. The perpendicular baseline is about $223 \mathrm{~m}$ and the ambiguity height is about $43 \mathrm{~m}$. The 3 arcsecond DEM data from the Shuttle Radar Topography Mission (SRTM) is used to remove the topographic phase [13]. Precise ERS-2 orbits from the Delft University of Technology are used in processing the data to reduce errors associated with image co-registration and flat earth phase removal [14-15]. The differential interferogram is then filtered with the improved Goldstein Filter to reduce the phase noises [16]. Finally the co-seismic interferogram of the earthquake is obtained as shown in Figure 2.

Figure 2. Co-seismic interferogram of Chi-Chi earthquake. Each interferometric fringe represents $2.8 \mathrm{~cm}$ of relative displacement in the radar LOS direction. The black line represents the Chelungpu fault. The inset diagram shows the corresponding coherence map. The value zero means that the signals are completely decorrelated and value unity fully coherent.

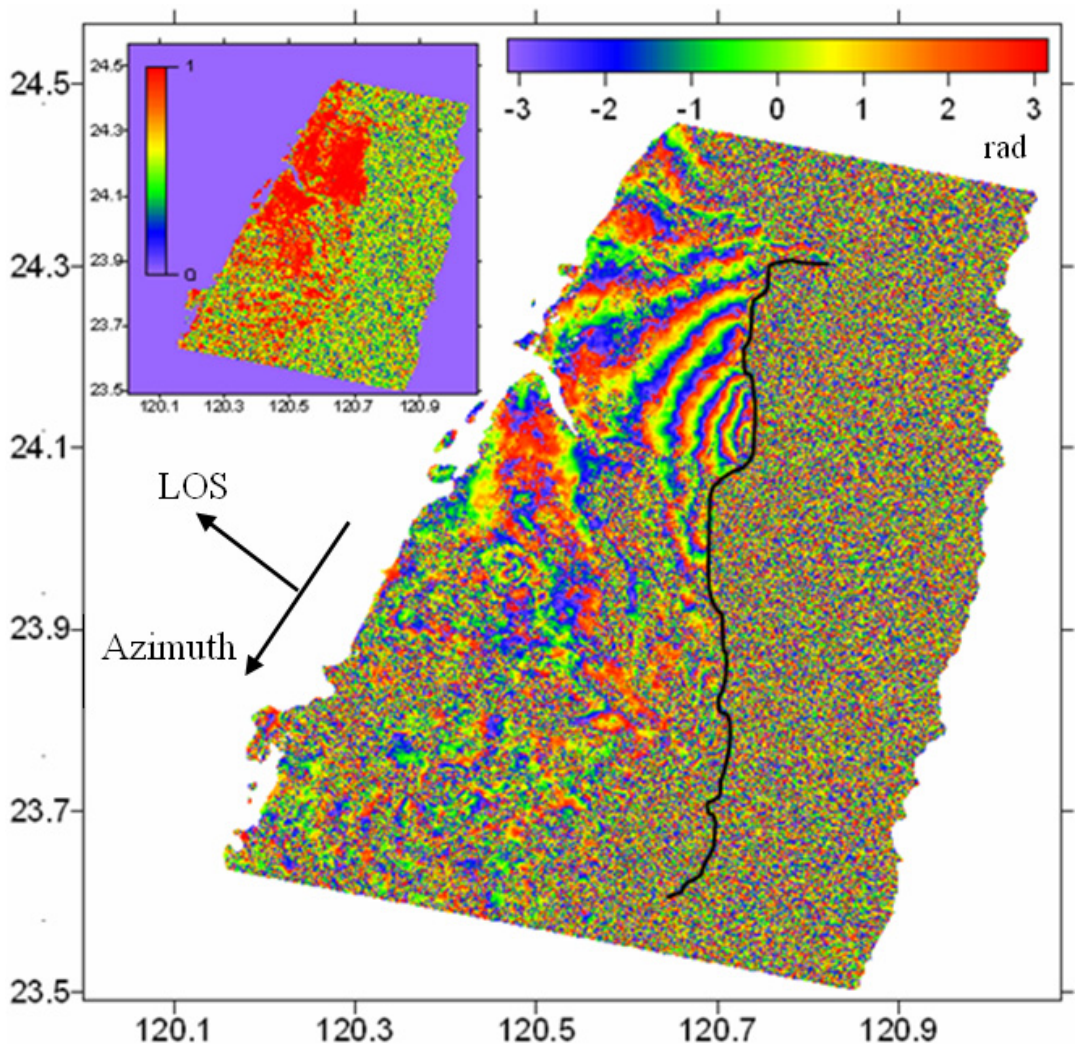

It can be seen from Figure 2 that there are about 7-8 fringes in the footwall side of the Chelungpu fault that are equivalent to about $21 \mathrm{~cm}$ of total relative radar range changes. Comparing with GPS 
results reported by $\mathrm{Yu}$ et al. [7], i.e., 2.4-10.1 m horizontal displacements and 1.2-4.4 $\mathrm{m}$ vertical displacements across the Chelungpu fault, it is known that only a very small fraction of the co-seismic displacements have been captured by the DInSAR method. In addition, no good DInSAR results on the hanging wall side of the Chelungpu fault have been reported as the area is covered by forest and serious decorrelaton has been experienced in the area $[5,17]$.

\subsection{Offsets Derived from Co-Seismic Amplitude Images}

A SAR image contains the phase as well as the amplitude information. We will in this study estimate the co-seismic displacements of the Chi-Chi earthquake with the method of SAR amplitude image matching. The principles of the method are based on the considerations that the post-seismic SAR amplitude image will have pixel-by-pixel shifts with respect to pixels of the pre-seismic SAR amplitude image and that the shift values can be determined through a correlation analysis. The shift values are directly related to the ground displacements caused by the earthquake. The shifts are in general estimated in two orthogonal directions, i.e., the azimuth and range directions, and are correspondingly called AZO and RO, respectively [18]. The amplitude image matching method measures sub-pixels position shifts and can in general achieve an accuracy of about 1/32 pixel [18].

To determine AZO and RO, the amplitude images first need to be co-registered. The co-registration will be implemented in two steps, i.e., coarse and fine co-registration. Preliminary offsets in the azimuth and range directions can be determined in the coarse co-registration. Finer scale offsets can then be calculated in the step of fine co-registration. The AZO and RO between the two amplitude images will be measured in their original sampling space, i.e., about $5 \mathrm{~m}$ in azimuth and $8 \mathrm{~m}$ in slant range directions. The window size used for estimating the correlation is $64 \times 64$ pixels. The accuracy of the measurements is about $15 \mathrm{~cm}$ in the azimuth direction and $25 \mathrm{~cm}$ in the slant range direction. For each pixel, the offset is [19]:

$$
R_{\text {offset }}=R_{\text {orbit }}+R_{\text {defo }}
$$

where $R_{\text {offset }}$ is related to the $\mathrm{AZO}$ and RO between the two images; $R_{\text {orbit }}$ represents the non-coseismic component that is due to the difference in the imaging geometries; $R_{\text {defo }}$ represents the surface displacement in the azimuth or range directions.

Figure 3 shows the calculated AZO and RO between the SAR images list in Table 1. Although there are significant systematic offsets, the trends of the displacements caused by the earthquake can be clearly seen.

The non-coseismic components due to the difference in the imaging geometries in Equation (1) needs to be removed in order to get the surface displacements. Wang et al. [20] suggested to model the non-coseismic components using a bilinear equation:

$$
R_{\text {orbit }}=a_{0}+a_{1} x+a_{2} y+a_{3} x y
$$

where $x$ and $y$ are the coordinates of the pixels in WGS 84 coordinate system, and $a_{0}, a_{1}, a_{2}$ and $a_{3}$ are coefficients accounting for the difference in the imaging geometries. 
Figure 3. The estimated of AZO (left) and RO (right). Unit: $\mathrm{m}$.
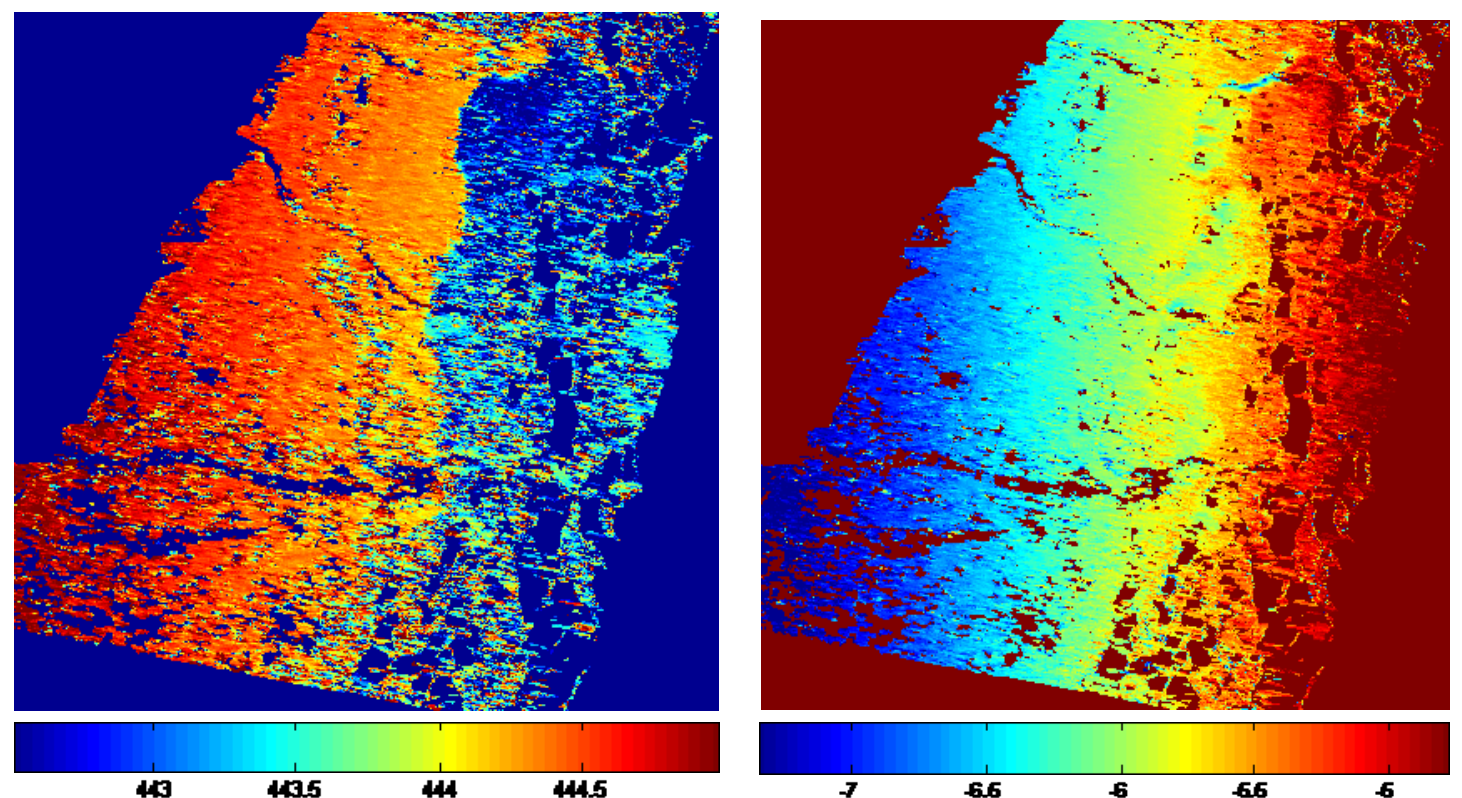

Ten of the 25 GPS stations in the study area given by Yu et al. [7] will be used as the Ground Control Points (GCP) in this study to help to estimate the non-coseismic components (See Figure 4). The 10 GPS stations selected are evenly distributed over the footwall area of the Chelungpu fault to cover well the displacement trend in the area. GPS observations can give three orthogonal components of the co-seismic displacements in the up, northern and eastern directions. Suppose that the vector $r=\left[\begin{array}{lll}r_{u} & r_{n} & r_{e}\end{array}\right]^{T}$ represents the three-dimensional (3D) displacements at a GPS site, the displacements vector can be converted into azimuth and range displacements $R_{\text {defo }}=\left[\begin{array}{ll}R_{A Z O} & R_{R O}\end{array}\right]^{T}$ following [20]

$$
R_{\text {defo }}=U \cdot r
$$

where $U$ is a matrix that consists of two unit projection vectors, one for the azimuth direction and the other for the range direction

$$
U=\left[\begin{array}{ccc}
0 & \cos \alpha & \sin \alpha \\
\cos \theta & \sin \alpha \sin \theta & -\cos \alpha \sin \theta
\end{array}\right]
$$

where $\theta$ is the radar incidence angle at the scattering target; and $\alpha$ is the azimuth angle of the satellite flight path (clockwise from the North). In the calculations, we define the up, northern and eastern directions as positive for $r_{u}, r_{n}$ and $r_{e}$. Similarly, we define the satellite flight direction as positive for $R_{A Z O}$, and the direction towards the satellite from the ground as positive for $R_{R O}$.

The non-coseismic component $R_{\text {orbit }}$ in Equation (1) at the 10 GCPs can be calculated with the azimuth and range displacements of the GCPs. The $R_{\text {orbit }}$ values thus calculated are then used to determine the coefficients $a_{0}, a_{1}, a_{2}$ and $a_{3}$ in Equation (2) in a least-squares solution. The coefficients are estimated for AZO and RO separately. The non-coseismic components thus obtained for the whole images are shown in Figure 5. Topographic variations can also cause non-coseismic range offsets. However, as such offsets are difficult to model and the baseline of the SAR pair is only $223 \mathrm{~m}$, the effect is neglected in this study. 
Figure 4. GPS stations used in the study. The yellow triangles represent the stations used as GCPs. The blue dots represent the stations used for validating the results. The inset diagram shows the geometry of radar image acquisition.

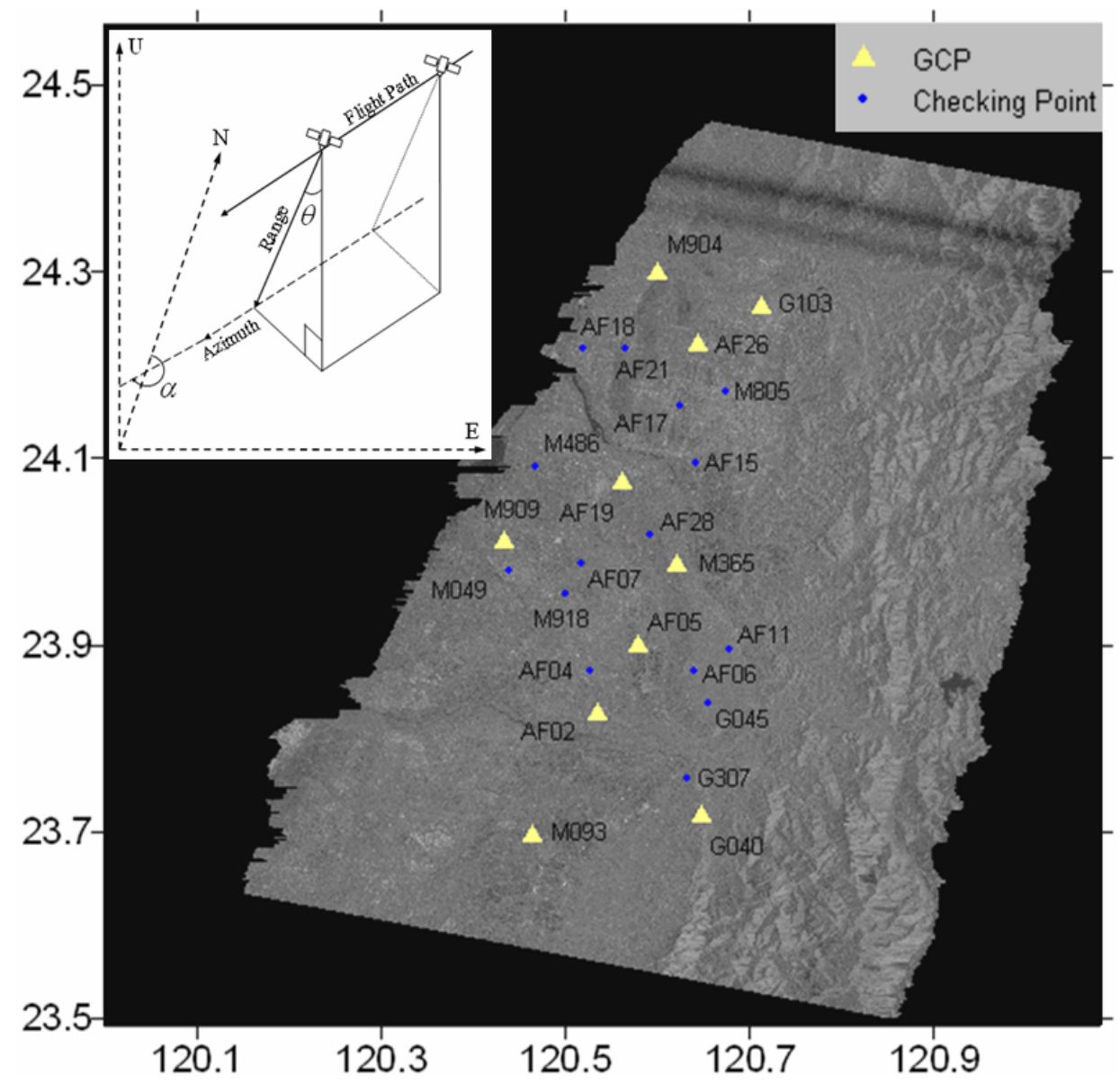

Figure 5. The non-coseismic components of AZO (left) and RO (right) estimated from the GPS observations. Units: $\mathrm{m}$.
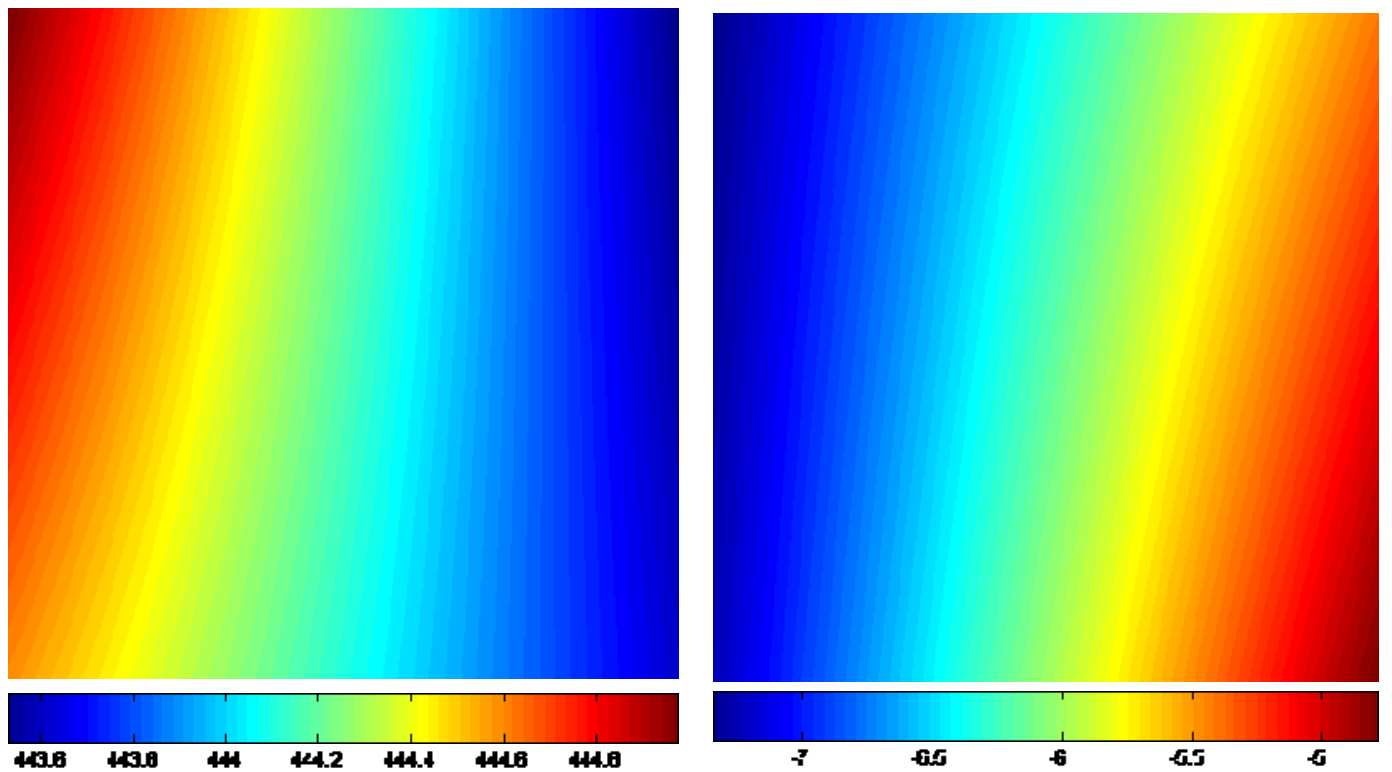


\section{Results}

Once the azimuth and range offsets and their corresponding non-coseismic components are determined, the azimuth and range displacements caused by the Chi-Chi earthquake can be easily computed by using Equation (1). The results are shown in Figure 6.

Figure 6. The ground surface displacements in (a) the azimuth and (b) the range directions.

The black solid line shows the location of the Chelungpu fault.
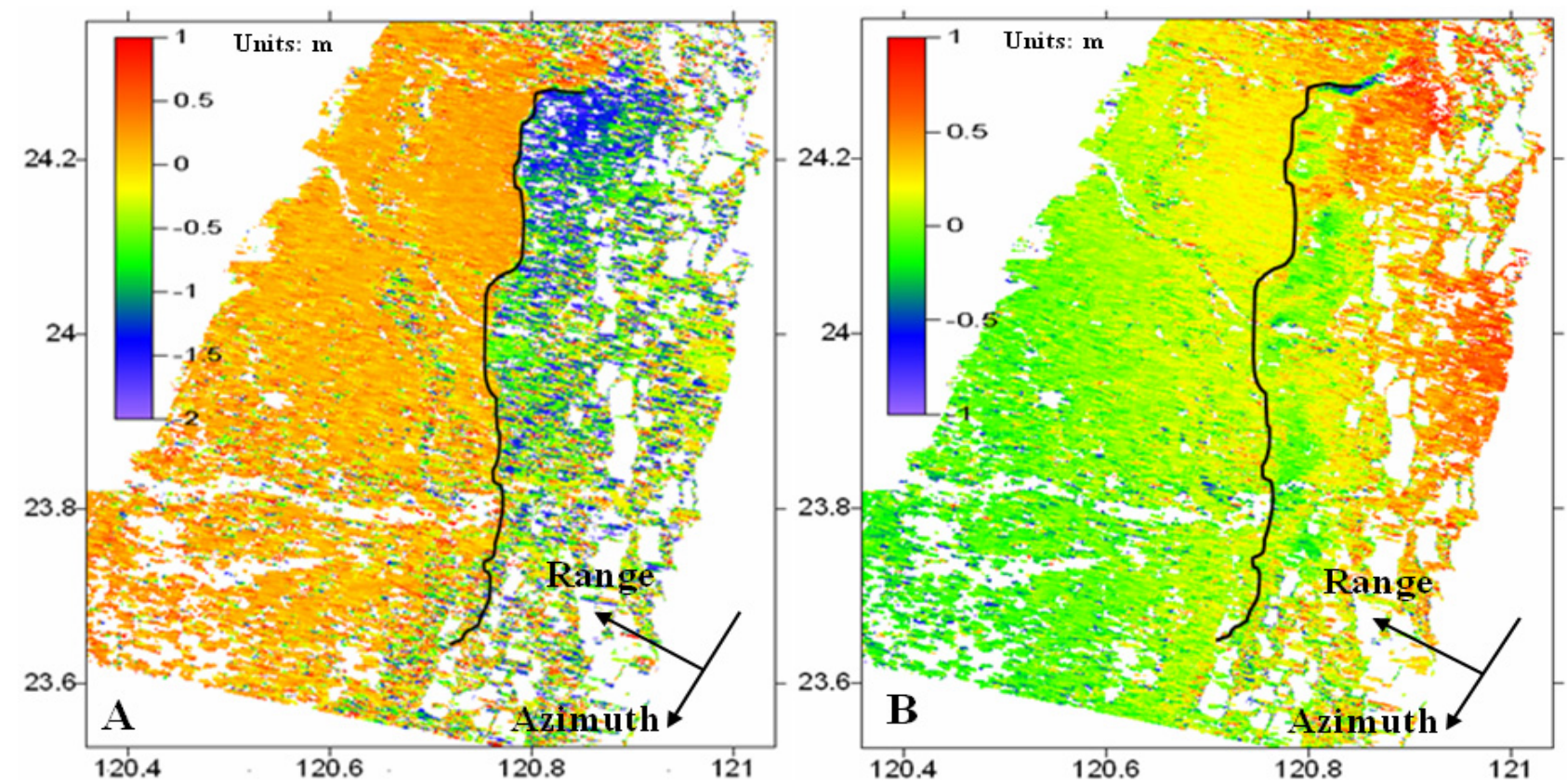

Figure 6A shows the ground displacements in the azimuth direction. It is clear that the co-seismic displacements range from about $-2.0 \mathrm{~m}$ to $0.7 \mathrm{~m}$ in this direction, with the footwall of the fault moving southwards and the hanging wall northwards. The results are very close to those derived from GPS measurements, with a mean discrepancy of less than $10 \mathrm{~cm}$ (see Figure 7). However, the displacement in the azimuth direction is difficult to highlight by the DInSAR method as it is almost perpendicular to the LOS direction. The recently developed sub-aperture InSAR method can potential help to determine the displacements in azimuth direction [23-24], however it will not be discussed here as it beyonds the scope of this research. The location of the Chelungpu fault can be easily identified in the displacement maps as the displacements on the two sides of the fault are largely in the opposite directions. The azimuth displacements in the hanging all are well over $0.5 \mathrm{~m}$, indicating that large-scale displacements have happened to the hanging wall of the fault.

The ground displacements in the range direction shown in Figure $6 \mathrm{~B}$ indicates that the earthquake caused displacements varying from about $-0.5 \mathrm{~m}$ to $1.0 \mathrm{~m}$ in this direction. However, only the displacements in the footwall of the fault, i.e., about $30 \mathrm{~cm}$, have been measured in this direction by the DInSAR method (see Figure 2, and [3-5]). The displacements in the hanging wall of the fault, i.e., $\sim 50 \mathrm{~cm}$, have never been measured with the DInSAR method as the severe decorrelation effect rendered the DInSAR method unusable in the area. Therefore, it is clear that the amplitude image matching method in this case offers much better information on the co-seismic ground displacements 
although in general the accuracy of the method is not as high as the DInSAR method due to the very low resolution of the ERS SAR images [18].

Figure 7. Comparisons between the displacements observed with GPS and from the method of amplitude image matching in azimuth (up) and range directions (low). The GPS stations used for the comparison are listed in Figure 4. The RMS values of the differences between the results are $6.9 \mathrm{~cm}$ and $5.7 \mathrm{~cm}$, respectively, in the two directions.
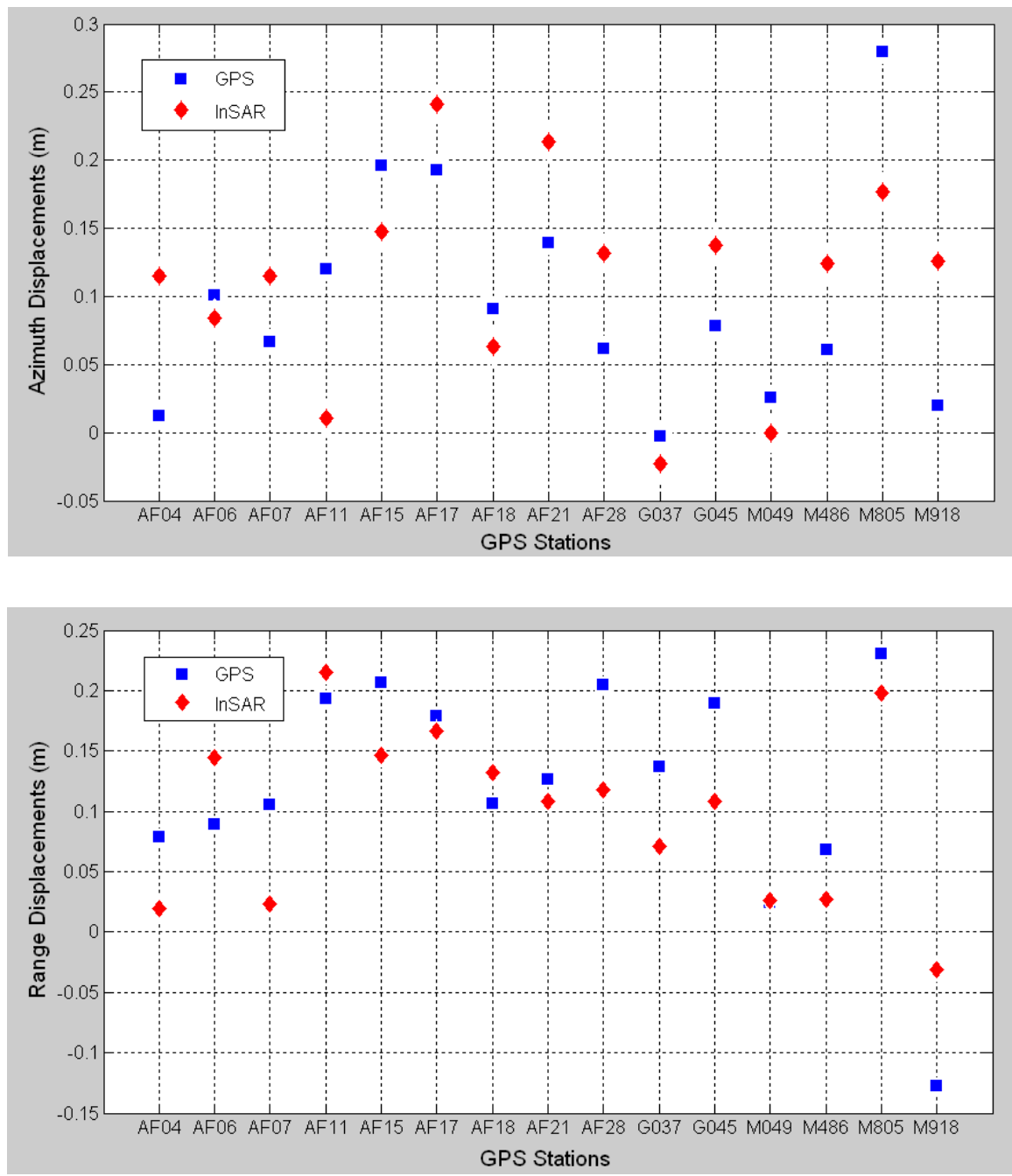

Fifteen additional GPS stations in the area are used to validate the results (See Figure 4). The up, northern and eastern components of the co-seismic displacements measured at the GPS stations are converted into the azimuth and range displacements and compared with those extracted from Figure 6. It can be seen from Figure 7 that the results from the two methods agree well with each other with the RMS values of the differences between the results being $6.9 \mathrm{~cm}$ and $5.7 \mathrm{~cm}$ in the azimuth and the range directions respectively.

\section{Conclusions}

A complete two-dimensional co-seismic ground deformation filed associated with the 1999 Chi-Chi earthquake in Taiwan has been generated from two descending ERS-2 SAR images with the SAR 
amplitude image matching method. DInSAR approach has not worked well in the area due to the severe decorrelation effect in the heavily vegetated mountainous regions. In addition, the DInSAR method has not been able to provide information on the displacements that perpendicular to the radar LOS direction, although the direction is important in this study as the Chelungpu fault trace is in the direction. The SAR amplitude image matching method on the other hand has worked very well in the study area. With the assistance of 10 GPS stations in the area, the co-seismic surface displacements in both the azimuth and range directions have been extracted successfully. Comparisons with the displacements observed at other 15 GPS stations have shown that the RMS values of the differences between the two types of results are $6.9 \mathrm{~cm}$ and $5.7 \mathrm{~cm}$ in the azimuth and range directions respectively. It is unfortunate that there are no suitable ascending ERS SAR images. Otherwise a 3D surface displacement field may be determined with the method and the least squares approaches [21].

\section{Acknowledgements}

We thank Dr. Charles L. Werner and Dr. Urs Wegmuller for their advices in the study and comments about SAR data processing using GAMMA software. This work was supported by the National Natural Science Foundation of China (Nos. 40774003 and 40404001), National High-Tech. “863" Program of China (No. 2006AA12Z156), Research Grants Council of the Hong Kong Special Administrative Region (Project No.: PolyU 5157/05E and PolyU5161/06E), and the Project of Western China 1:50000 Topography Mapping. The ERS data used in this study were provided by the European Space Agency under category 1 user projects (AO-4458 and 4914). We thank one of the anonymous reviewers for their wonderful work that help to significantly improve the quality of the paper, both in terms of scientific content and clarity of presentation

\section{References and Notes}

1. Chang, C.P.; Wang, C.T.; Chang, T.Y.; Chen, K.S.; Liang, L.S.; Pathier, E. Application of SAR interferometry to a large thrust deformation: the $1999 M_{w}=7.6$ Chi-Chi earthquake in central Taiwan. Geophys. J. Int. 2004, 159, 9-16.

2. Suga, Y.; Takeuchi, S.; Oguro, Y.; Chen, A.J.; Ogawa, M.; Konishi, T.; Yonezawa, C. Application of ERS-2/SAR data for the 1999 Taiwan earthquake. Adv. Space Res. 2001, 28, 155 163.

3. Pathier, E.; Fruneau, B.; Deffontaines, B.; Angelier, J.; Chang, C.P.; Yu, S.B.; Lee, C.T. Coseismic displacements of the footwall of the Chelungpu fault caused by the 1999, Taiwan, ChiChi earthquake from InSAR and GPS data. Earth Planet. Sci. Lett. 2003, 212, 73-88.

4. Liu, G.X.; Ding, X.L.; Chen, Y.Q.; Li, Z.L. Crustal deformation mapping with Satellite SAR interferometry: applied to 1999 Chi-Chi, Taiwan earthquake. Abstract of Eos Transactions, $A G U$ 2002 Fall Meeting. San Fransisco, California, December 6-10 2002; 83.

5. Liu, G.X.; Ding, X.L.; Li, Z.L.; Li, Z.W.; Chen, Y.Q.; Yu, S.B. Pre- and co-seismic ground deformations of the 1999 Chi-Chi, Taiwan earthquake, measured with SAR interferometry. Comput. Geosci. 2004, 30, 333-343.

6. Just, D; Bamler, R. Phase statistics of interferograms with applications to synthetic aperture radar. Appl. Optics. 1994, 33, 4361-4368. 
7. Yu, S.B.; Kou, L.C.; Hsu, Y.J.; Su, H.H.; Liu, C.C.; Hou, C.S.; Lee, J.F.; Lai, T.C.; Liu, C.C.; Liu, C.L.; Tseng, T.F.; Tsai, C.S.; Shin, T.C. Preseismic deformation and coseismic displacements Associated with the 1999 Chi-Chi, Taiwan, earthquake. Bull. Seismol. Soc. Am. 2001, 91, 9951012.

8. Michel, R.; Avouac, J.P.; Taboury, J. Measuring near field coseismic displacements from SAR images: Application to the Landers earthquake. Geophys. Res. Lett. 1999, 26, 3017-3020.

9. Michel, R.; Avouac, J.P.; Taboury, J. Measuring ground displacements from SAR amplitude images: Application to the Landers earthquake. Geophys. Res. Lett. 1999, 26, 875-878.

10. Fialko, Y.; Sandwell, D.; Simons, M.; Rosen, P. Three-dimensional deformation caused by the Bam, Iran, earthquake and the origin of shallow slip deficit. Nature 2005, 435, 295-299.

11. Simons, M.; Fialko, Y.; Rivera, L. Coseismic deformation from the $1999 \mathrm{Mw} 7.1$ Hector Mine, California, earthquake as inferred from InSAR and GPS observations. Bull. Seismol. Soc. Am. 2002, 92, 1390- 1402 .

12. Werner, C.; Wegmüller, U.; Strozzi, T.; Wiesmann, A. Gamma SAR and Interferometric Processing Software. Proc. ERSENVISAT Symposium, Gothenburg, Sweden, Oct. 16-20 2000.

13. Farr, M.; Kobrick, M. Shuttle radar topography mission produces awealth of data. EOS Transactions 2000, 81, 583-585.

14. Scharoo, R.; Visser, P. Precise orbit determination and gravity field improvement for the ERS satellites. J. Geophys. Res. 1998, 103, 8113-8127.

15. ERS Precise Orbit Determination, Department of Earth Observation \& Space Systems, Delft University of Technology. http://www.deos.tudelft.nl/ers/precorbs/orbits/ (access on April 26 2008)

16. Li, Z.W.; Ding, X.L.; Huang, C.; Zheng, D.W.; Zou, W.B.; Shea, Y.K. Filtering method for radar interferogram with strong noise. Int. J. Remote Sens. 2006, 27, 2991-3000.

17. Zhang, L.; Wu, J.C.; Ge, L.L.; Ding, X.L.; Chen, Y.L. Determining fault slip distribution of the Chi-Chi Taiwan earthquake with GPS and InSAR data using triangular dislocation elements. $J$. Geodyn. 2007, 45, 163-168.

18. Werner, C.; Wegmuller, U.; Strozzi, T.; Wiesmam, A. Precision estimation of local offsets between pairs of SAR SLCs and detected SAR images. In: International Geoscience and Remote Sensing Symposium, Seoul, Korea. 2005; 4803-4805.

19. Liu, H.X.; Zhao, Z.Y.; Yu, J.Y.; Jezek, K. Simultaneous least squares adjustment of multiframe velocities derived from interferometric and Speckle-Tracking methods. IEEE Geosci. Remote Sens. Lett. 2008, 5, 289-293.

20. Wang, H.; Ge, L.L.; Xu, C. J. 3-D Coseimic displacement field of the 2005 Kashmir earthquake inferred from satellite radar imagery. Earth Planets Space 2007, 59, 343-349.

21. Tobita, M.; Murakami, M.; Nakagawa, H.; Yarai, H.; Fujiwara, S. 3-D surface deformation of the 2000 Usu eruption measured by matching of SAR images. Geophys. Res. Lett. 2001, 28, 42914294.

22. Dominguez, S.; Avouac, J.-P.; Michel, R. Horizontal coseismic deformation of the 1999 Chi-Chi earthquake measured from SPOT satellite images: Implications for the seismic cycle along the western foothills of central Taiwan. J. Geophys. Res. 2003, 108(B2), 2083-2101. 
23. Bechor, N.B.D.; Zebker, H.A. Measuring two-dimensional movements using a single InSAR pair. Geophys. Res. Lett. 2006, 33, L16311.

24. Barbot, S.; Hamiel, Y.; Fialko, Y. Space geodetic investigation of the coseismic and postseismic deformation due to the $2003 M_{w} 7.2$ Altai earthquake: Implications for the local lithospheric rheology. J. Geophys. Res. 2008, 113, B03403.

(C) 2008 by the authors; licensee Molecular Diversity Preservation International, Basel, Switzerland. This article is an open-access article distributed under the terms and conditions of the Creative Commons Attribution license (http://creativecommons.org/licenses/by/3.0/). 